Article

\title{
Structural, Hirshfeld Surface Analysis, Morphological Approach, and Spectroscopic Study of New Hybrid Iodobismuthate Containing Tetranuclear 0D Cluster $\mathrm{Bi}_{4} \mathrm{I}_{16} \cdot 4\left(\mathrm{C}_{6} \mathrm{H}_{9} \mathrm{~N}_{2}\right) 2\left(\mathrm{H}_{2} \mathrm{O}\right)$
}

\author{
Hela Ferjani \\ Chemistry Department, College of Science, IMSIU (Imam Mohammad Ibn Saud Islamic University), \\ Riyadh 11623, Saudi Arabia; hhferjani@imamu.edu.sa
}

Received: 20 April 2020; Accepted: 13 May 2020; Published: 15 May 2020

\begin{abstract}
The $\mathrm{Bi}_{4} \mathrm{I}_{16} \cdot 4\left(\mathrm{C}_{6} \mathrm{H}_{9} \mathrm{~N}_{2}\right) 2\left(\mathrm{H}_{2} \mathrm{O}\right)$ compound was synthesized by slow evaporation at room temperature. It exhibits a zero-dimensional (0D) tetrameric structure, comprising $\left[\mathrm{Bi}_{4} \mathrm{I}_{16}\right]^{4-}$ distorted octahedra, with strong I $\cdots$ I interactions among adjacent anionic clusters. We used Hirshfeld surface analysis to discuss the strength of hydrogen bonds and to quantify the inter-contacts (two-dimensional (2D) fingerprint plots). It revealed that the hydrogen bonding interactions $\mathrm{H} \cdots \mathrm{I}(56.3 \%), \pi-\pi$ stacking $(11.7 \%)$, and $\mathrm{I} \cdots \mathrm{I}$ interactions $(5.9 \%)$ play the major role in the stability of the crystal structure. The crystal morphology was simulated using Bravais-Friedel, Donnay-Harker (BFDH) and growth morphology (GM) methods. The experimental habit of the title compound was adequately reproduced by the two models. The calculated results show that the crystal morphology of the title compound in a vacuum is dominated by five facets: (020), (011), (110), (10-1), and (11-1). The (020) facet is the largest among all the facets calculated. Projection of the facet showed that there are a few polar groups on the (020) facet. In the 50-400 and $400-4000 \mathrm{~cm}^{-1}$ frequency regions, we measured the Raman and infrared spectra, respectively, of the title compound, and we assigned the observed vibration modes.
\end{abstract}

Keywords: iodobismuthate; tetranuclear cluster; 1-allylimidazole; crystal morphology; Hirshfeld surface analysis; infrared and Raman spectroscopy

\section{Introduction}

As a significant type of hybrid material, organic-inorganic hybrid materials (OIHM) based on halogenometallates attracted remarkable attention in recent years, due to their structural diversity and several physical properties arising from the mixture between organic and inorganic parts. Many studies concentrated on the synthesis and characterization of such materials [1-6]. However, hybrid materials based on bismuth were paid special attention owing to their diverse structures, developing a variety of ferroelectric and Ferro-elastic devices [7-11], with novel thermochromic, optical, and electrical properties [12-15]. Halogenobismuthate (III)-based materials occupy an exceptional place for the replacement of lead-based compounds in photovoltaic cells [16-19]. These compounds are unaffected by humidity like lead compounds. According to the literature, these materials can exhibit a great diversity of anionic sublattices built from different linkages of $\mathrm{BiX}_{6}(\mathrm{X}=\mathrm{Cl}, \mathrm{Br}$, and I) octahedra including corner-, edge-, or face-sharing modes [20-26]. Furthermore, the supramolecular assemblies of halogenobismuthate compounds depend on some parameters, such as bonds, coordination geometries around the metal center, the nature of the ligands, the metal-ligand stoichiometry, and the different experimental conditions such as solvents, temperature, the concentration of hydro-halogenic acid, and crystallization methods. For instance, this complex presents the new salt isolated by 1-allylimidazole in the crystalline state from diluted HI. From the Cambridge Crystallographic Database, 1-allylimidazole 
is a good template that is rarely studied, presenting both rigidity and flexibility. In recent times, flexible and rigid organic templates were often used to build interesting structures due to their influence on the arrangement of the inorganic networks. It is worth mentioning that the supramolecular arrangement is controlled by different kinds of electrostatic interactions such as hydrogen bonds, $\pi-\pi$ interactions, and halogen $\cdots$ halogen contacts. Thus, to examine these interactions inside the supramolecular arrangement, it is important to study their quantitative measurements.

Here, we report the synthesis of new perovskite-like hybrid iodobismuthate $\mathrm{Bi}_{4} \mathrm{I}_{16} \cdot 4\left(\mathrm{C}_{6} \mathrm{H}_{9} \mathrm{~N}_{2}\right)$ $2\left(\mathrm{H}_{2} \mathrm{O}\right)$. We discuss the crystal structure and the spectroscopic behavior. The intermolecular interactions were described by Hirshfeld surface analysis. The theoretical crystal morphology was calculated showing a big similarity with the experimental one.

\section{Materials and Methods}

\subsection{Synthesis}

Crystals of $\mathrm{Bi}_{4} \mathrm{I}_{16} \cdot 4\left(\mathrm{C}_{6} \mathrm{H}_{9} \mathrm{~N}_{2}\right) 2\left(\mathrm{H}_{2} \mathrm{O}\right)$ were synthesized by slow evaporation at room temperature. Firstly, we dissolved, in an aqueous solution, 1-allylimidazole (0 $3 \mathrm{~g}, 2 \mathrm{mmol})$ and $\mathrm{HI}\left(3 \mathrm{~mL}\right.$ of $\mathrm{H}_{2} \mathrm{O}$ and $2 \mathrm{~mL}$ of $\mathrm{HI}, 57 \%)$. Then, $\mathrm{Bi}_{2} \mathrm{O}_{3}(0.65 \mathrm{~g}, 1 \mathrm{mmol})$ was dissolved in $10 \mathrm{~mL}$ of $\mathrm{H}_{2} \mathrm{O}$ and $5 \mathrm{~mL}$ of $\mathrm{HI}$ and stirred for $30 \mathrm{~min}$. The two solutions were mixed together and stirred for four hours with heating $\left(50{ }^{\circ} \mathrm{C}\right)$. The saturated orange solution was put in the dark for evaporation at room temperature. After three days, block orange crystals were formed.

\subsection{Crystal Data and Structure Determination}

A Bruker D8 Quest (Madison, WI, USA) diffractometer $\left(\mathrm{MoK}_{\alpha}\right.$ radiation $\lambda=0.71073 \AA$ ) was used to collect the single-crystal X-ray data at $298 \mathrm{~K}$, via the Bruker APEX3 software package [27]. SAINT [28] was executed for data reduction. Multi-scan absorption correction was accomplished using SADABS [29]. The SHELXS (Madison, WI, USA) and SHELXTL (Madison, WI, USA) packages were used to solve the structure via direct methods, and the program SHELXL-2014 was performed to refine the structure using full-matrix least squares procedures on $\mathrm{F}^{2}$ [30]. All non-hydrogen atoms were refined with anisotropic displacement parameters. Hydrogen atoms were located at calculated positions using a riding model. We could not locate the hydrogen atoms of water molecules but we included them in the formula. Diamond 3 was used to prepare the molecular graphics [31]. Table 1 shows details of the data collection and crystallographic parameters. Table S1 (Supplementary Materials) provides the atomic coordinates and equivalent isotropic displacement parameters. Some interatomic distances and bond angles are given in Table 2.

\subsection{Physicochemical Characterization}

A Nicolet NXR Fourier-transform infrared (FT-IR) spectrometer (Dhahran, Saudi Arabia) was used to record the FT-IR spectrum in the $400-4000 \mathrm{~cm}^{-1}$ region at room temperature on a $\mathrm{KBr}$ disc. The Raman spectrum was recorded using a HORIBA Lab RAM HR Evolution Surface-Enhanced Raman Scattering Microscope (Dhahran, Saudi Arabia) in the $400-50 \mathrm{~cm}^{-1}$ region. The morphology of the sample was observed using a JEOL, JSM-6380-LA electron microscope (Riyadh, Saudi Arabia). The working distance was $15 \mathrm{~mm}$ with an accelerating voltage of $10 \mathrm{kV}$.

\subsection{Simulation Details}

\subsubsection{Hirshfeld Surface Analysis}

The Crystal Explorer 3.1 program (Perth, Australia) was used to create the Hirshfeld molecular surfaces and their relative two-dimensional (2D) fingerprint plots [32,33]. The normalized contact distance $d_{\text {norm }}$ [34] based on Bondi's van der Waals radii [35] and 2D fingerprint plots were used for quantifying and decoding the inter-contacts in the crystal packing. The intense red color arises as a 
result of contacts shorter than the sum of van der Waals radii, which are indicated by negative values of $d_{\text {norm}}$. The other intermolecular distances close to van der Waals contacts, with $d_{\text {norm }}$ equal to zero, appear as light-red spots. In turn, contacts with positive $d_{\text {norm }}$ values which are longer than the sum of van der Waals radii are colored with blue. Furthermore, $d_{e}$ (inside) and $d_{i}$ (outside) represent the distance from the point to the nearest nucleus external and internal to the surface with respect to the relative van der Waals radii. The intermolecular interactions in the crystal are summarized by the combination of $d_{e}$ and $d_{i}$ in the form of a 2D fingerprint plot.

The enrichment ratio $E_{X Y}$ for a pair of elements $(X, Y)$ is defined as the ratio between the proportion of actual contacts in the crystal $\left(\mathrm{C}_{\mathrm{XY}}\right)$ and the theoretical proportion of equi-distributed random contacts $\mathrm{R}_{X Y}[36]$.

$$
E_{X Y}=C_{X Y} / R_{X Y}
$$

A pair of elements has a high tendency to form contacts in the crystal if their enrichment ratio is larger than unity, while pairs which have an E value lower than unity tend to avoid contact with each other.

\subsubsection{Computer Morphology Simulation}

The crystal morphology predictions were created using a preliminary equilibration procedure, by means of the Forcite tools implemented in the Material Studio 7.0 package (San Diego, CA, USA) of Accelrys [37], assuming the molecular mechanics approximation and the Universal Force Field (UFF) [38]. The crystal structures used to simulate morphology were determined from the cif file containing all the crystallographic information. The morphology process was based on the Bravais-Friedel, Donnay-Harker (BFDH) and growth morphology (GM) methods. The minimum interplanar distance $\left(\mathrm{d}_{\mathrm{hkl}}\right)$ for facet list generation was set to $1 \AA$, with a maximum value of 5 for the Miller indices and no limit for the overall number of growing facets. The crystal morphology simulation was achieved in vacuum and, consequently, it did not take into account any experimental conditions.

\section{Results and Discussion}

\subsection{Energy-Dispersive X-ray Spectroscopy (SEM-EDX)}

SEM image (Figure S1, Supplementary Materials) analysis shows that the surfaces of the hybrid appeared in the form of flat surfaces, which designates a good crystal quality. The EDX analysis associated with the SEM was carried out in zones of high contrast. The EDX measurements were conducted to confirm the presence of heavy element compositions of the crystal. They show the presence of characteristic carbon, iodine, bismuth, and oxygen signals.

\subsection{Structure Description}

The title compound $\mathrm{Bi}_{4} \mathrm{I}_{16} \cdot 4\left(\mathrm{C}_{6} \mathrm{H}_{9} \mathrm{~N}_{2}\right) 2\left(\mathrm{H}_{2} \mathrm{O}\right)$ crystallizes in the monoclinic space group $P 2_{1} / n$ (Table 1). Half of the $\left(\mathrm{Bi}_{4} \mathrm{I}_{16}\right)^{4-}$ anion of the structure sits on a crystallographic inversion center; two 1-allylimidizalium cations $\left(\mathrm{C}_{6} \mathrm{H}_{9} \mathrm{~N}_{2}\right)^{+}$and one water molecule complete the asymmetric unit (Figure 1). Each $\mathrm{Bi}(\mathrm{III})$ atom is six-coordinated by $\mathrm{I}$ atoms in a distorted octahedral geometry, and each $\mathrm{BiI}_{6}$ octahedron is linked to another by two I atoms, forming a tetranuclear centrosymmetric cluster via edge-sharing. There are three types of I atoms: (i) I4 and I $4^{i}$ [symmetry code: (i) $1-x, 1-y, 1-z$ ] bridge three bismuth centers ( $\mu_{3}$-I); (ii) I2, I $2^{\mathrm{i}}$ [symmetry code: (i) $1-\mathrm{x}, 1-\mathrm{y}, 1-\mathrm{z}$ ], I5, and $\mathrm{I}^{\mathrm{i}}$ bridge two bismuth centers $\left(\mu_{2}-\mathrm{I}\right)$; (iii) the remaining I atoms (I1, I3, I5, I6, I7, I8) are terminally bonded to Bi atoms. The range of B-I bonds is 2.8898 (7)-3.3309 (6) $\AA$, with a range of 3.3196 (6)-3.3309 (6) $\AA$ for bonds involving $\left(\mu_{3}-\mathrm{I}\right)$ atoms and $3.0228(6)-3.1416(6) \AA$ for bonds involving $\left(\mu_{2}-\mathrm{I}\right)$ atoms. The bond angles I-Bi-I range between of $84.369(15)^{\circ}$ and $96.58(3)^{\circ}$, suggest the high distortion of octahedra (Table 2). The shortest I6 $\cdots I 7^{\mathrm{ii}}$ [symmetry code: (ii) $\mathrm{x}-1 / 2, \mathrm{y}-3 / 2, \mathrm{z}-1 / 2$ ] distance is 3.8603(10) $\AA$, which is shorter than the sum of van der Waals radii of two iodine atoms (4.3 $\AA$ ) [39]. This indicates the presence of strong I.-I interactions. All bond distances and angles of this cluster are in agreement with 
the related iodobismuthate compounds [40-42]. The packing diagram for $\mathrm{Bi}_{4} \mathrm{I}_{16} \cdot 4\left(\mathrm{C}_{6} \mathrm{H}_{9} \mathrm{~N}_{2}\right) \cdot 2\left(\mathrm{H}_{2} \mathrm{O}\right)$ is shown in Figure 2, where it is observed that the organic-inorganic (110) layers stack in a slightly offset ABAB manner. The supramolecular hydrogen-bonding patterns associated with both imidazolium groups of the $\left(\mathrm{C}_{6} \mathrm{H}_{9} \mathrm{~N}_{2}\right)^{+}$cation in the title compound are shown in Figure 3. The terminal $\mathrm{N}-\mathrm{H}$ moieties in $\left(\mathrm{C}_{6} \mathrm{H}_{9} \mathrm{~N}_{2}\right)^{+}$cations act as hydrogen-bond donors with three iodine vertices of two isolated $\left(\mathrm{Bi}_{4} \mathrm{I}_{16}\right)^{4-}$ anions via N2-H2N … I3 and N2-H2N ... I1 interactions (Table 3). The water molecules connect the organic cations using $\mathrm{N} 4-\mathrm{H} 4 \mathrm{~N} \cdots \mathrm{O} 1 \mathrm{~W}$ hydrogen bonds, $\pi-\pi$ interactions with imidazolium rings, oxygen-centroid distances of 3.43 (1) A, and oxygen-centroid of allyl group distances of 3.66 (1) $\AA$. The organic cations are also interconnected by $\pi-\pi$ interactions between allyl groups and imidazolium rings (centroid allyl-centroid imidazolium ring distances of 4.03 (2) Å), as shown in Figure 4. Therefore, I...I interactions, hydrogen bonds, and $\pi-\pi$ interactions contribute to the structural stabilization.

Table 1. Crystallographic data and structure refinement parameters for $\mathrm{Bi}_{4} \mathrm{I}_{16} \cdot 4\left(\mathrm{C}_{6} \mathrm{H}_{9} \mathrm{~N}_{2}\right) 2\left(\mathrm{H}_{2} \mathrm{O}\right)$.

\begin{tabular}{|c|c|}
\hline Empirical Formula & $\mathrm{Bi}_{4} \mathrm{I}_{16} \cdot 4\left(\mathrm{C}_{6} \mathrm{H}_{9} \mathrm{~N}_{2}\right) \cdot 2\left(\mathrm{H}_{2} \mathrm{O}\right)$ \\
\hline Formula weight (g/mol) & 3338.96 \\
\hline Crystal system, space group & Monoclinic, $P 2_{1} / n$ \\
\hline$a(\AA)$ & $11.312(6)$ \\
\hline$b(\AA)$ & $25.985(2)$ \\
\hline$c(\AA)$ & $11.879(7)$ \\
\hline$\beta\left(^{\circ}\right)$ & $110.05(2)$ \\
\hline $\mathrm{V}\left(\AA^{3}\right)$ & $3280(3)$ \\
\hline $\mathrm{Z}$ & 2 \\
\hline$\mu\left(\mathrm{mm}^{-1}\right)$ & 18.26 \\
\hline$D_{\mathrm{x}}\left(\mathrm{Mg} \cdot \mathrm{m}^{-3}\right)$ & 3.381 \\
\hline$F(000)$ & 3.381 \\
\hline Crystal size (mm) & $0.34 \times 0.33 \times 0.20$ \\
\hline Crystal habit & Block, orange \\
\hline$\theta_{\min } / \theta_{\max }\left(^{\circ}\right)$ & $2.5 / 28.4$ \\
\hline Measured reflections & 113,427 \\
\hline Independent reflections & 8177 \\
\hline Observed reflections with $\mathrm{I}>2 \sigma(\mathrm{I})$ & 6751 \\
\hline $\mathrm{R}_{\text {int }}$ & 0.116 \\
\hline Data/restraints/parameters & $8177 / 0 / 245$ \\
\hline $\mathrm{R}\left[\mathrm{F}^{2}>2 \sigma\left(\mathrm{F}^{2}\right)\right]$ & 0.042 \\
\hline $\mathrm{wR}\left(\mathrm{F}^{2}\right)$ & 0.091 \\
\hline $\mathrm{GooF}=\mathrm{S}$ & 1.086 \\
\hline$\Delta \rho_{\max } / \Delta \rho_{\min }\left(\mathrm{e} \AA^{-3}\right)$ & $1.55 /-1.39$ \\
\hline
\end{tabular}

Table 2. Selected bond distances and angles of $\mathrm{Bi}_{4} \mathrm{I}_{16} \cdot 4\left(\mathrm{C}_{6} \mathrm{H}_{9} \mathrm{~N}_{2}\right) \cdot 2\left(\mathrm{H}_{2} \mathrm{O}\right)$.

\begin{tabular}{cccc}
\hline \multicolumn{4}{c}{ Bond Distances (Ả) } \\
\hline Bi1-I3 & $2.9033(6)$ & Bi2-I6 & $2.8918(7)$ \\
Bi1-I1 & $2.9219(6)$ & Bi2-I7 & $2.9581(6)$ \\
Bi1-I2 & $3.0228(6)$ & Bi2-I5 & $3.2456(6)$ \\
Bi1-I5 & $3.1416(6)$ & Bi2-I2 ${ }^{\text {i }}$ & $3.3271(6)$ \\
Bi1-I4 & $3.3196(6)$ & Bi2-I4 & $3.3418(6)$ \\
Bi1-I4 ${ }^{\text {i }}$ & $3.3309(6)$ & I2-Bi2 ${ }^{\text {i }}$ & $3.3272(6)$ \\
Bi2-I8 & $2.8898(7)$ & I4-Bi1 ${ }^{\text {i }}$ & $3.3308(6)$ \\
\hline \multicolumn{4}{c}{ Bond Angles $\left(^{\circ}\right)$} \\
I3-Bi1-I1 & $92.74(2)$ & I8-Bi2-I6 & $96.58(3)$ \\
I3-Bi1-I2 & $89.82(2)$ & I8-Bi2-I7 & $95.71(2)$ \\
I1-Bi1-I2 & $94.571(2)$ & I6-Bi2-I7 & $91.90(2)$ \\
I3-Bi1-I5 & $93.38(2)$ & I8-Bi2-I5 & $87.97(2)$ \\
I1-Bi1-I5 & $90.259(2)$ & I6-Bi2-I5 & $90.35(2)$ \\
I2-Bi1-I5 & $174.073(2)$ & I7-Bi2-I5 & $175.43(2)$ \\
\hline
\end{tabular}


Table 2. Cont.

\begin{tabular}{cccc}
\hline I3-Bi1-I4 & $90.346(2)$ & I8-Bi2-I2 $^{\text {i }}$ & $85.10(2)$ \\
I1-Bi1-I4 & $176.274(2)$ & I6-Bi2-I2 $^{\text {i }}$ & $178.23(2)$ \\
I2-Bi1-I4 & $87.516(2)$ & I7-Bi2-I2 $^{\text {i }}$ & $88.458(2)$ \\
I5-Bi1-I4 & $87.479(2)$ & I5-Bi2-I2 ${ }^{\text {i }}$ & $89.170(2)$ \\
I3-Bi1-I4 ${ }^{\text {i }}$ & $174.67(2)$ & I8-Bi2-I4 & $167.43(2)$ \\
I1-Bi1-I4 ${ }^{\text {i }}$ & $92.564(2)$ & I6-Bi2-I4 & $94.14(2)$ \\
I2-Bi1-I4 ${ }^{\text {i }}$ & $89.226(2)$ & I7-Bi2-I4 & $90.443(2)$ \\
I5-Bi1-I4 ${ }^{\text {i }}$ & $87.124(16)$ & I5-Bi2-I4 & $85.427(2)$ \\
I4-Bi1-I4 ${ }^{\text {i }}$ & $84.369(15)$ & I2i-Bi2-I4 & $84.122(2)$ \\
\hline \multicolumn{5}{c}{ Symmetry code: (i) -x + 1,-y + 1,-z + 1. }
\end{tabular}

Symmetry code: (i) $-x+1,-y+1,-z+1$.

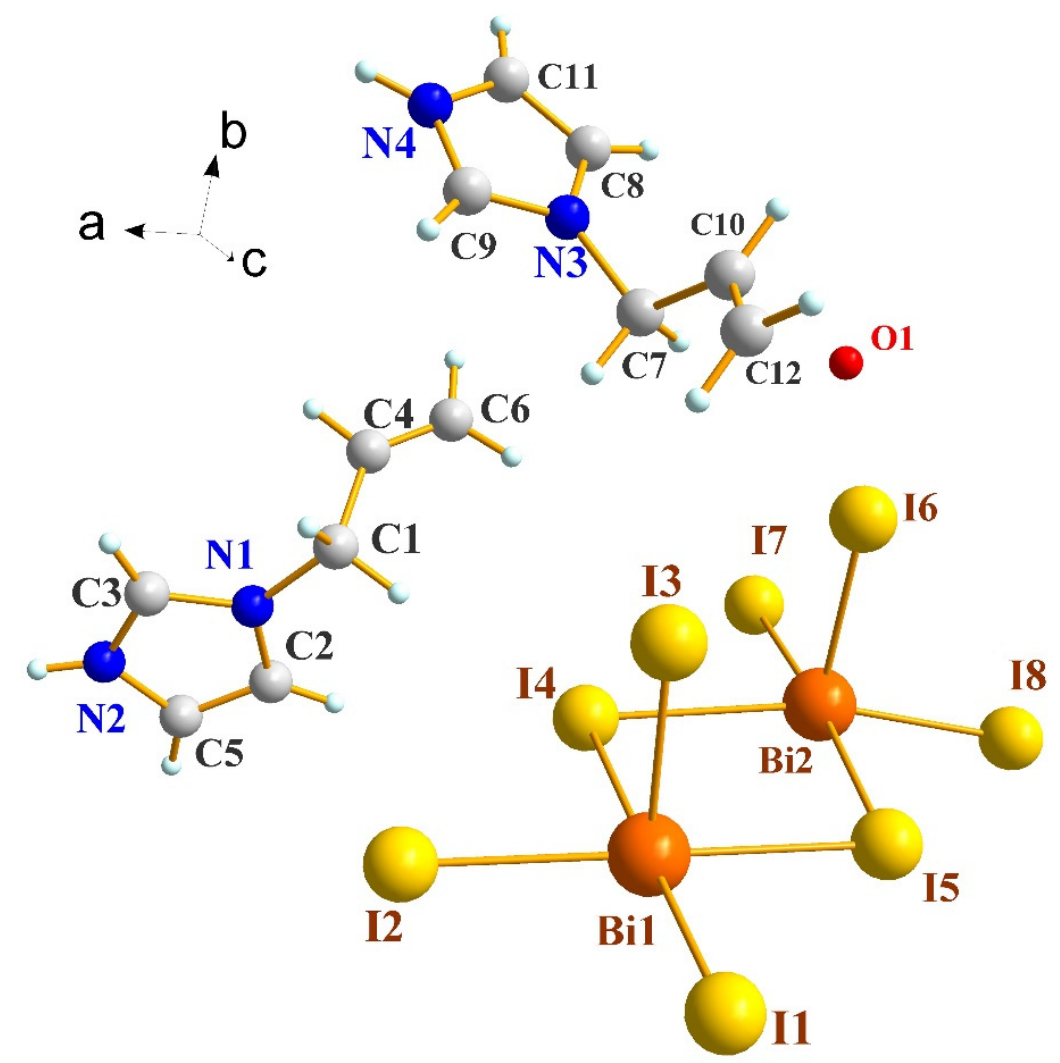

Figure 1. The asymmetric unit of $\mathrm{Bi}_{4} \mathrm{I}_{16} \cdot 4\left(\mathrm{C}_{6} \mathrm{H}_{9} \mathrm{~N}_{2}\right) \cdot 2\left(\mathrm{H}_{2} \mathrm{O}\right)$, showing the atomic numbering scheme.

Table 3. Hydrogen bonds in $\mathrm{Bi}_{4} \mathrm{I}_{16} \cdot 4\left(\mathrm{C}_{6} \mathrm{H}_{9} \mathrm{~N}_{2}\right) 2\left(\mathrm{H}_{2} \mathrm{O}\right)$.

\begin{tabular}{|c|c|c|c|c|}
\hline H-Bonds & D-H & H·A (Å) & 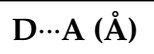 & $<(\mathrm{DH} \cdots \mathrm{A})\left(^{\circ}\right)$ \\
\hline N4-H4‥O1W & 0.86 & 1.96 & $2.79(2)$ & 162 \\
\hline 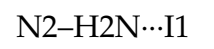 & 0.86 & $3.42(6)$ & $3.89(1)$ & 126 \\
\hline N2-H2N $\cdots$ I3 & 0.86 & $3.48(8)$ & $3.97(1)$ & 125 \\
\hline
\end{tabular}




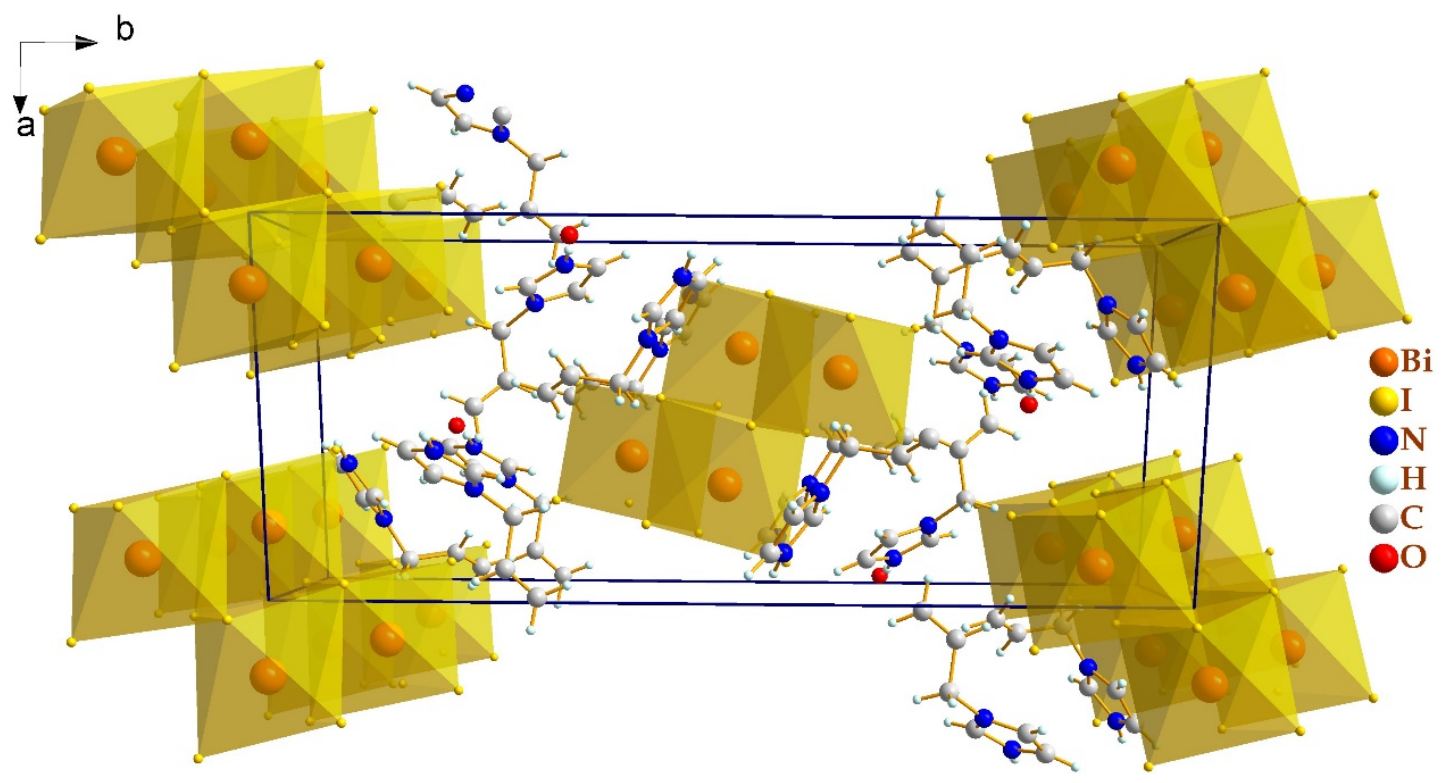

Figure 2. The (110) view of the crystal packing in $\mathrm{Bi}_{4} \mathrm{I}_{16} \cdot 4\left(\mathrm{C}_{6} \mathrm{H}_{9} \mathrm{~N}_{2}\right) \cdot 2\left(\mathrm{H}_{2} \mathrm{O}\right)$.

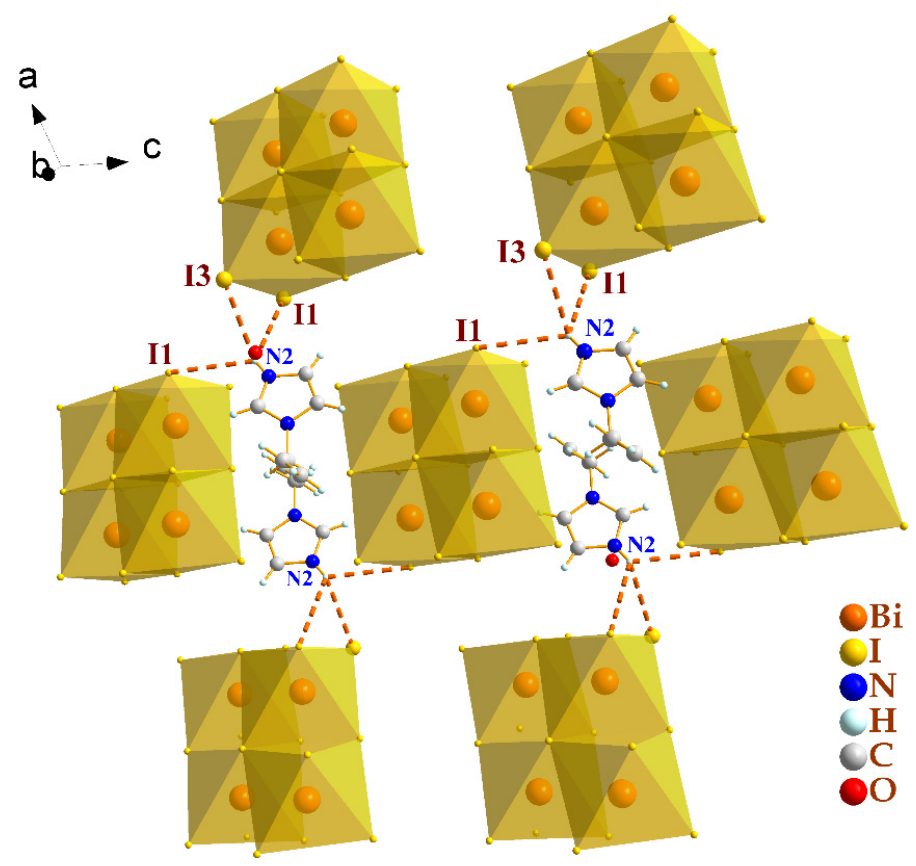

Figure 3. The hydrogen-bonding scheme of $\mathrm{Bi}_{4} \mathrm{I}_{16} \cdot 4\left(\mathrm{C}_{6} \mathrm{H}_{9} \mathrm{~N}_{2}\right) \cdot 2\left(\mathrm{H}_{2} \mathrm{O}\right)$.

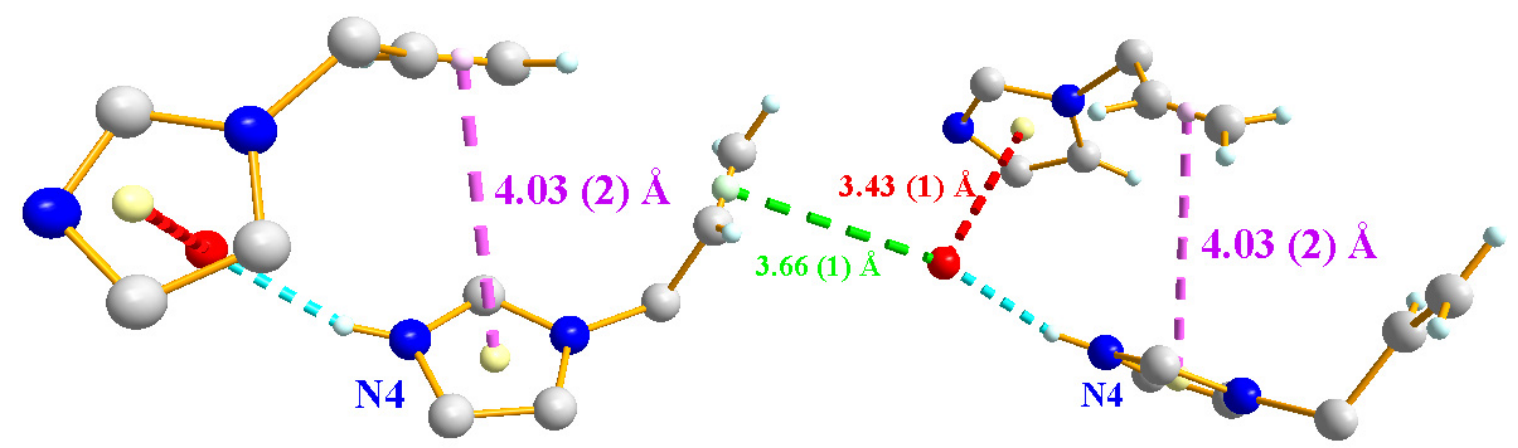

Figure 4. The $\pi-\pi$ interactions between organic cations and water molecules in $\mathrm{Bi}_{4} \mathrm{I}_{16} \cdot 4\left(\mathrm{C}_{6} \mathrm{H}_{9} \mathrm{~N}_{2}\right)$ $2\left(\mathrm{H}_{2} \mathrm{O}\right)$. 


\subsection{Hirshfeld Surface Analysis}

The nature of intermolecular interactions in $\mathrm{Bi}_{4} \mathrm{I}_{16} \cdot 4\left(\mathrm{C}_{6} \mathrm{H}_{9} \mathrm{~N}_{2}\right) 2\left(\mathrm{H}_{2} \mathrm{O}\right)$ was clarified using three-dimensional Hirshfeld surface analysis. The 2D fingerprint plots quantitatively revealed the contribution of those interactions in the crystal structure, presenting the surfaces that were mapped over a $d_{\text {norm }}$ range of -0.614 to $1.100, d_{e}$ range of 0.737 to 3.166 , and $d_{i}$ range of 0.737 to 3.062 (Figure 5). The information of these surfaces is summarized in Table 3 . The deep-red regions visible on the views of the $d_{\text {norm }}$ surfaces represent hydrogen-bonding contacts: $\mathrm{H} \cdots \mathrm{I}$ and $\mathrm{H} \cdots \mathrm{O}$. The bright-red regions on the $d_{e}$ surface focus on the hydrogen bond acceptor $I \cdots H$, where $d_{e}$ is short, but the hydrogen bond donor $\mathrm{H} \cdots \mathrm{I}$ is observed as the red area of the $\mathrm{d}_{\mathrm{i}}$ surface (Figure 5). The greatest contribution from the $\mathrm{I} \cdots \mathrm{H} / \mathrm{H} \cdots \mathrm{I}$ contacts is $56.3 \%$, corresponding to $\mathrm{N}-\mathrm{H} \cdots \mathrm{I}$ interactions, as illustrated by a pair of sharp spikes characteristic of strong hydrogen-bonding interactions in the 2D fingerprint plot (Figure 6).

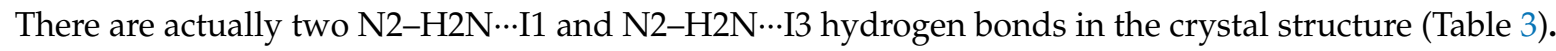
Furthermore, these types of contacts are the most common interactions due to the abundance of iodine and hydrogen on the molecular surface $\left(\% \mathrm{~S}_{\mathrm{I}}=39.7 \%\right.$ and $\left.\% \mathrm{~S}_{\mathrm{H}}=45.6 \%\right)$ and an enrichment ratio higher than the unit $\mathrm{E}_{\mathrm{H} \cdots \mathrm{I}}=1.55$ (Table 4). In addition, the $\mathrm{H} \cdots \mathrm{H}$ interactions appear as a large region of the 2D fingerprint plot with a high concentration in the middle region, comprising $11.7 \%$ of the total Hirshfeld surface area (Figure 6); they are the second most frequent interactions due to the richness of hydrogen on the molecular surface $(45.6 \%)$. The $\mathrm{H} \cdots \mathrm{O}$ contacts, which refer to $\mathrm{N}-\mathrm{H} \cdots \mathrm{O}$ interactions, represent the third most important interaction on the surface with a percentage around $8.1 \%$ of the Hirshfeld surfaces (Figure 6) and an enrichment ratio higher than unit $\mathrm{E}_{\mathrm{H} \cdots \mathrm{O}}=1.39$ (Table 4).

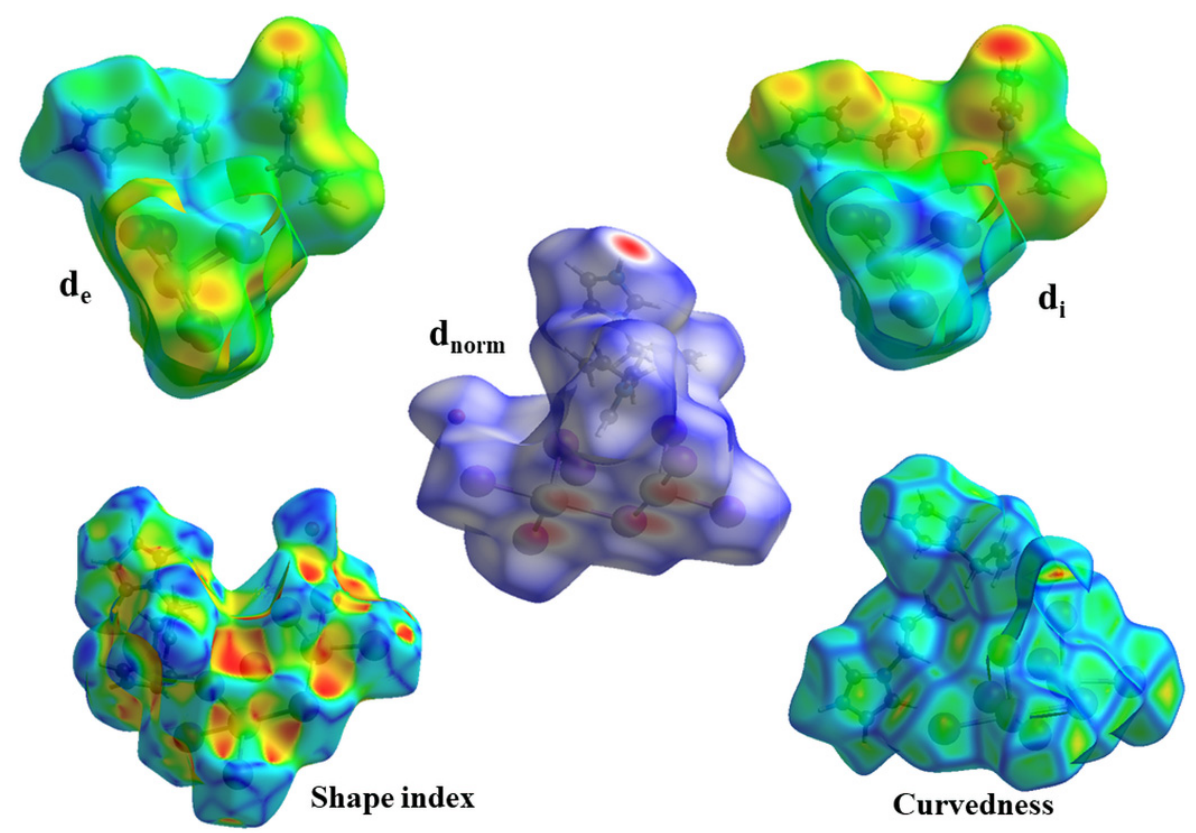

Figure 5. $d_{\text {norm }}$ mapped on Hirshfeld surfaces for visualizing the intermolecular interactions, $d_{e}, d_{i}$, curvedness, and shape-index of $\mathrm{Bi}_{4} \mathrm{I}_{16} \cdot 4\left(\mathrm{C}_{6} \mathrm{H}_{9} \mathrm{~N}_{2}\right) 2\left(\mathrm{H}_{2} \mathrm{O}\right)$.

Shape index and curvedness surfaces, illustrated in Figure 5, were used to discover planar stacking $(\pi \cdots \pi)$ interaction arrangements. In the same region of the shape index surface, the presence of red and blue triangles in Figure 5 indicates that the $\pi \cdots \pi$ interactions are identically present in the crystal structure. Blue triangles represent the convex region which is formed due to the carbon and nitrogen atoms present in the molecule inside the surface, while red triangles having concave regions are due to the carbon atoms of $\pi$-stacked molecule above it. The mapping of curvedness on the Hirshfeld surface Figure 5 shows flat green regions separated by blue edges. The clearly visible flat regions on the curvedness surface are another characteristic of the $\pi \cdots \pi$ stacking interaction. The contribution of $\pi \cdots \pi$ stacking interactions ( $\mathrm{O} \cdots \mathrm{C}$ and $\mathrm{C} \cdots \mathrm{C}$ ) was also investigated by Hirshfeld surfaces, as shown 
in Figure 7. The O $\cdots \mathrm{C}$ contacts contribute $1.7 \%$ to the total Hirshfeld surface area, which is a small percentage. The $\mathrm{C} \cdots \mathrm{C}$ contacts are a rare $0.3 \%$ of the total Hirshfeld surface area, but more enriched at $\mathrm{E}_{\mathrm{C} \cdots \mathrm{C}}=1.87$ due to stacking between imidazole rings and allyl groups. The $\mathrm{H} \cdots \mathrm{H}$ interactions are reflected in the distribution of scattered points in the 2D fingerprint plot, which have a relatively significant contribution of $11.7 \%$ to the total Hirshfeld surface area of the molecules, but these contacts are slightly under-represented with an enrichment ratio around 0.56 . The Hirshfeld surfaces of the bismuth atom in the compound, which were mapped over the $d_{\text {norm }}$ surface, show deep-red regions for $\mathrm{Bi}$, highlighting the short $\mathrm{Bi} \cdots \mathrm{I}$ and $\mathrm{I} \cdots \mathrm{I}$ contacts. The $\mathrm{Bi} \cdots \mathrm{I}$ and $\mathrm{I} \cdots \mathrm{I}$ contacts contribute $5.5 \%$ and $5.9 \%$ of the Hirshfeld surfaces, respectively. Thus, the Hirshfeld surface analysis adequately confirms the presence of the I...I interaction discussed in the structural description. Figure 7 presents the relative percentage contributions to the overall Hirshfeld surface. In conclusion, the Hirshfeld surface analysis elucidates the same results as the X-ray crystal structure analysis and explains the intermolecular interactions in a new visual manner.

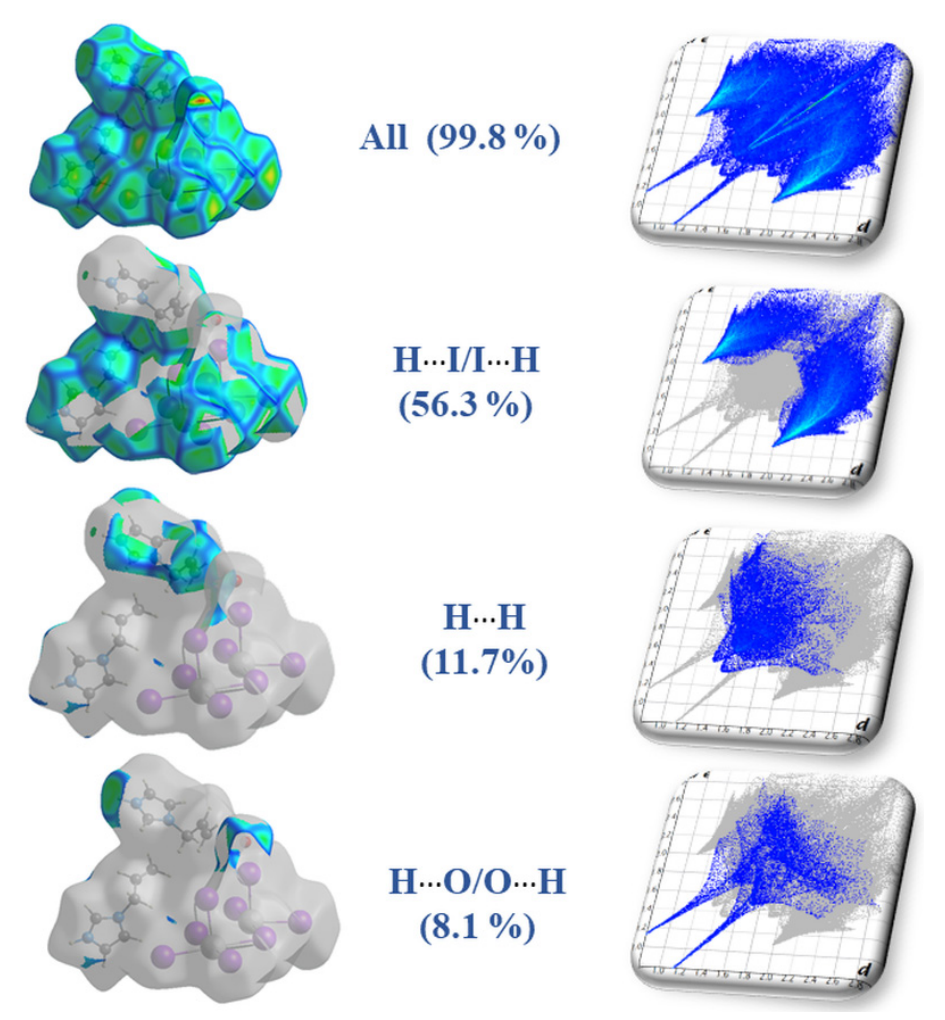

Figure 6. Fingerprint plots with $\mathrm{d}_{\text {norm }}$ view of $\mathrm{H} \cdots \mathrm{I}, \mathrm{H} \cdots \mathrm{H}$, and $\mathrm{H} \cdots \mathrm{O}$ contacts in $\mathrm{Bi}_{4} \mathrm{I}_{16} \cdot 4\left(\mathrm{C}_{6} \mathrm{H}_{9} \mathrm{~N}_{2}\right) \cdot 2\left(\mathrm{H}_{2} \mathrm{O}\right)$.

Table 4. Hirshfeld contact surfaces and enrichment ratios for $\mathrm{Bi}_{4} \mathrm{I}_{16} \cdot 4\left(\mathrm{C}_{6} \mathrm{H}_{9} \mathrm{~N}_{2}\right) \cdot 2\left(\mathrm{H}_{2} \mathrm{O}\right)$.

\begin{tabular}{ccccccc}
\hline Atoms & $\mathbf{H}$ & $\mathbf{C}$ & $\mathbf{N}$ & $\mathbf{O}$ & $\mathbf{I}$ & $\mathbf{B i}$ \\
\hline Surface $\%$ & $\mathbf{4 5 . 6}$ & 4 & 1.75 & 6.2 & 39.7 & 2.75 \\
$\mathrm{H}$ & 0.56 & - & - & - & - & - \\
$\mathrm{C}$ & 0.74 & 1.87 & - & - & - & - \\
$\mathrm{N}$ & 0.24 & - & 0.00 & - & - & - \\
$\mathrm{O}$ & 1.39 & - & - & 0.00 & - & - \\
$\mathrm{I}$ & 1.55 & 0.69 & - & 0.64 & 0.37 & - \\
$\mathrm{Bi}$ & 0.00 & 0.00 & 0.00 & 0.00 & - & 0.00 \\
\hline
\end{tabular}




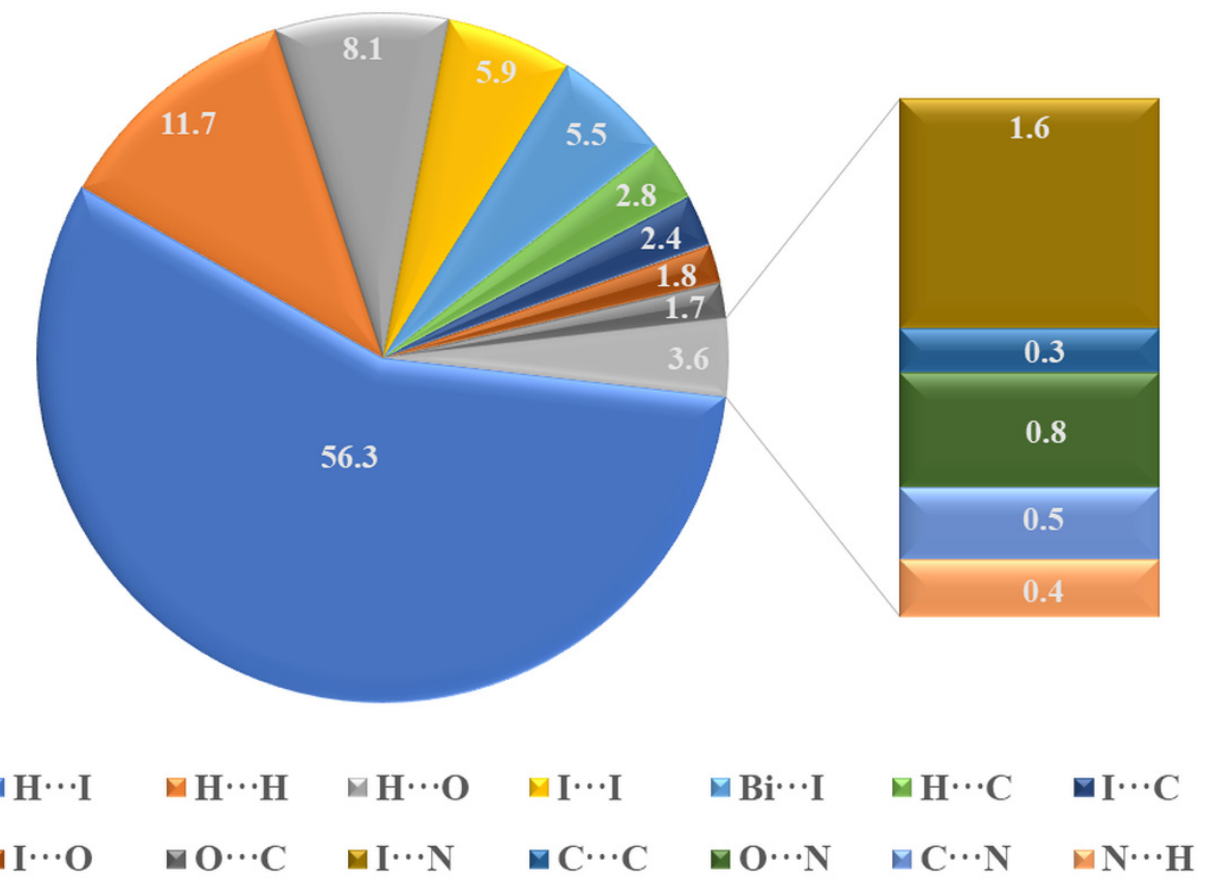

Figure 7. Relative contributions of different intermolecular contacts to the Hirshfeld surface area in $\mathrm{Bi}_{4} \mathrm{I}_{16} \cdot 4\left(\mathrm{C}_{6} \mathrm{H}_{9} \mathrm{~N}_{2}\right) 2\left(\mathrm{H}_{2} \mathrm{O}\right)$.

\subsection{Prediction of Crystal Morphology}

Figure 8 shows that there is an extraordinary similarity between the simulated crystal morphology based on BFDH and growth morphology (GM) methods (Figure 8b,c) and the experimental one (Figure 8a) assessed by scanning electronic microscopy (SEM).

The vacuum morphology of $\mathrm{Bi}_{4} \mathrm{I}_{16} \cdot 4\left(\mathrm{C}_{6} \mathrm{H}_{9} \mathrm{~N}_{2}\right) 2\left(\mathrm{H}_{2} \mathrm{O}\right)$ was generated by the $\mathrm{BFDH}$ model (Figure $8 b$ ), which gave five important facets along with their planes (hkl), center-to-plane distance $\left(\mathrm{d}_{\mathrm{hkl}}\right)$, and \% surface area. The BFDH method is an approximation where facet growth rates are assumed to be inversely proportional to the interplanar spacings $d_{h k l}$ in the lattice [43]. Table 5 lists the inter-planar spacings of various low index facets of the crystal habit of the title compound based on the BFDH calculation. It shows that the crystal facets are made up by (020), (011), (110), (10-1), and (11-1) planes, of which (020) with $28.84 \%$ of the total facet area was the most important facet. The calculated aspect ratio by BFDH morphology was 1.713. In the second step, morphology was determined by the GM method, which shows (Table 5 and Figure 8c) that the crystal facets are dominated by (020), (011), (110), (10-1), and (11-1) planes, of which (020) with $30.77 \%$ and (10-1) with $27.26 \%$ of total facet area were the most important facets. The calculated aspect ratio for the GM model was 1.88. Figure 9 show the result analysis of morphology prediction by the GM method, illustrating the hkl plane corresponding to the morphological important crystal facets described in the habit, while simply taking into account which types of groups are extended from the considered facet. It is evident that the (020) and (10-1) morphological importance facets, which represent more than the $57 \%$ of the crystal surface, are occupied by a small number of polar groups (small interactions). The attachment energies of (020) and $(10-1)$ are -32.0392 and $-33.1538 \mathrm{~kJ} \cdot \mathrm{mol}^{-1}$, respectively. The other morphological important facets demonstrate the presence of polar functional groups (stronger interactions). The attachment energy calculations were performed to explain the probable energetic interactions during crystal growth. If the attachment energy is the lowest in a particular direction, the morphologically important facet bounding that growth direction has the slowest growth rate and will be the smallest [44]. According to the $E_{\text {att }}$ value, the (11-1) and (011) facets present the stronger interaction and their growth rates are also faster than that of the (020), (10-1), and (110) facets. 
Table 5. Morphology predictions for $\mathrm{Bi}_{4} \mathrm{I}_{16} \cdot 4\left(\mathrm{C}_{6} \mathrm{H}_{9} \mathrm{~N}_{2}\right) \cdot 2\left(\mathrm{H}_{2} \mathrm{O}\right)$ through Bravais-Friedel, DonnayHarker (BFDH) (upper) and growth morphology (GM) (lower) calculations. The percentage of total facet area (TFA) is calculated as $100 \times(\mathrm{hkl}$ facet area)/(total surface area).

\begin{tabular}{|c|c|c|c|c|}
\hline \multicolumn{5}{|c|}{ BFDH } \\
\hline hkl & \multicolumn{2}{|c|}{ Multiplicity } & $\mathrm{D}_{\mathrm{hkl}}(\AA)$ & $\%$ of TFA \\
\hline$\left(\begin{array}{llll}0 & 2 & 0\end{array}\right)$ & \multicolumn{2}{|l|}{2} & 12.99 & 28.84 \\
\hline$\left(\begin{array}{llll}0 & 1 & 1\end{array}\right)$ & \multicolumn{2}{|l|}{4} & 10.25 & 28.64 \\
\hline$\left(\begin{array}{lll}1 & 1 & 0\end{array}\right)$ & \multicolumn{2}{|l|}{4} & 9.84 & 25.60 \\
\hline$\left(\begin{array}{lll}1 & 0 & -1\end{array}\right)$ & \multicolumn{2}{|l|}{2} & 9.49 & 9.73 \\
\hline$\left(\begin{array}{lll}1 & 1 & -1\end{array}\right)$ & \multicolumn{2}{|l|}{4} & 8.92 & 7.19 \\
\hline \multicolumn{5}{|c|}{ Growth Morphology } \\
\hline hkl & Multiplicity & $d_{h k l}(\AA)$ & 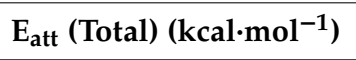 & $\%$ of TFA \\
\hline$\left(\begin{array}{llll}0 & 2 & 0\end{array}\right)$ & 2 & 12.99 & -32.0392 & 30.77 \\
\hline$\left(\begin{array}{lll}1 & 0 & -1\end{array}\right)$ & 2 & 9.49 & -33.1538 & 27.26 \\
\hline$\left(\begin{array}{lll}1 & 1 & 0\end{array}\right)$ & 4 & 9.84 & -39.0501 & 20.81 \\
\hline$\left(\begin{array}{llll}0 & 1 & 1\end{array}\right)$ & 4 & 10.25 & -51.9067 & 13.96 \\
\hline$\left(\begin{array}{lll}1 & 1 & -1\end{array}\right)$ & 4 & 8.91 & $-58,9835$ & 7.10 \\
\hline
\end{tabular}

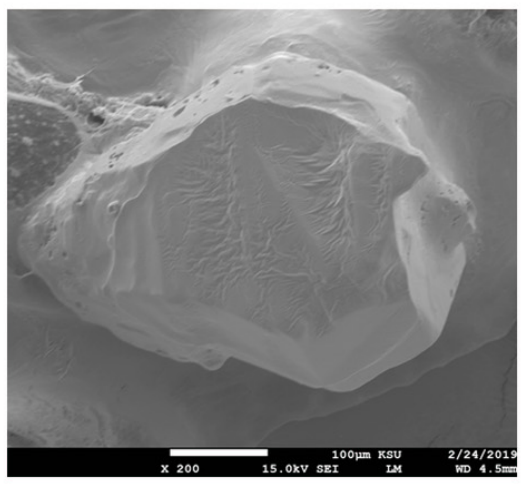

(a)

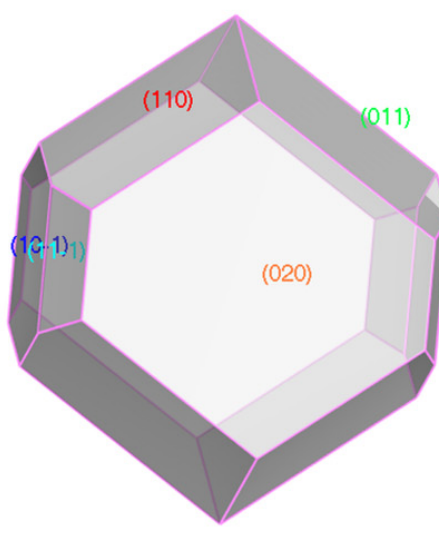

(b)

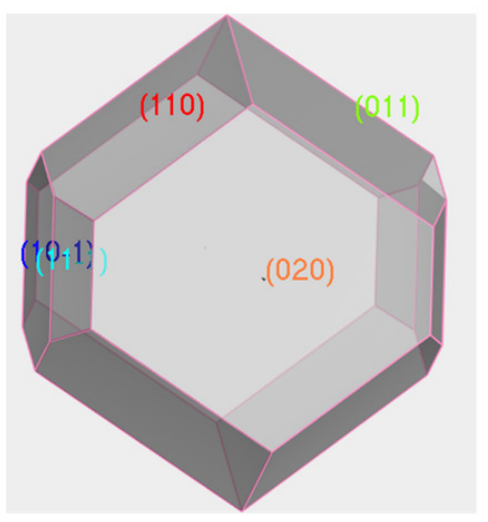

(c)

Figure 8. Crystal morphology comparison between the SEM images (a); BFDH model (b); GM model (c). The morphologically important (MI) facets are presented by their Miller indices.

\subsection{Infrared (IR) and Raman Spectroscopy}

IR and Raman spectroscopy were completed to give information on the molecular interactions existing in $\mathrm{Bi}_{4} \mathrm{I}_{16} \cdot 4\left(\mathrm{C}_{6} \mathrm{H}_{9} \mathrm{~N}_{2}\right) 2\left(\mathrm{H}_{2} \mathrm{O}\right)$. The tentative assignment of the internal vibrations of the allylimidazolium cations is based on the previously reported vibrational studies on materials containing the allylimidazolium cation [45]. The assignments of the internal vibrations of the $\left(\mathrm{Bi}_{4} \mathrm{I}_{16}\right)^{4-}$ anions are proposed on the basis of the results obtained for numerous halogenobismuthate (III) derivatives [46-49].

The Raman spectrum (Figure 10) recorded in the $50-400 \mathrm{~cm}^{-1}$ frequency range showed six bands at $63 \mathrm{~cm}^{-1}, 94 \mathrm{~cm}^{-1}, 80 \mathrm{~cm}^{-1}, 108 \mathrm{~cm}^{-1}, 124 \mathrm{~cm}^{-1}$ and $144 \mathrm{~cm}^{-1}$ associated with the inorganic cluster. The strong Raman line at $144 \mathrm{~cm}^{-1}$ clearly corresponds to the symmetric Bi-I stretching mode of the external iodides. In turn, the feeble Raman line near $124 \mathrm{~cm}^{-1}$ is due to the asymmetric Bi-I stretching mode. The stretching modes for the bridged I-Bi-I give a weak Raman line at $108 \mathrm{~cm}^{-1}$. The additional weak bands visible at $63 \mathrm{~cm}^{-1}, 94 \mathrm{~cm}^{-1}$ and $80 \mathrm{~cm}^{-1}$ may be assigned to the bending modes of the external iodides and the bridged I-Bi-I. 


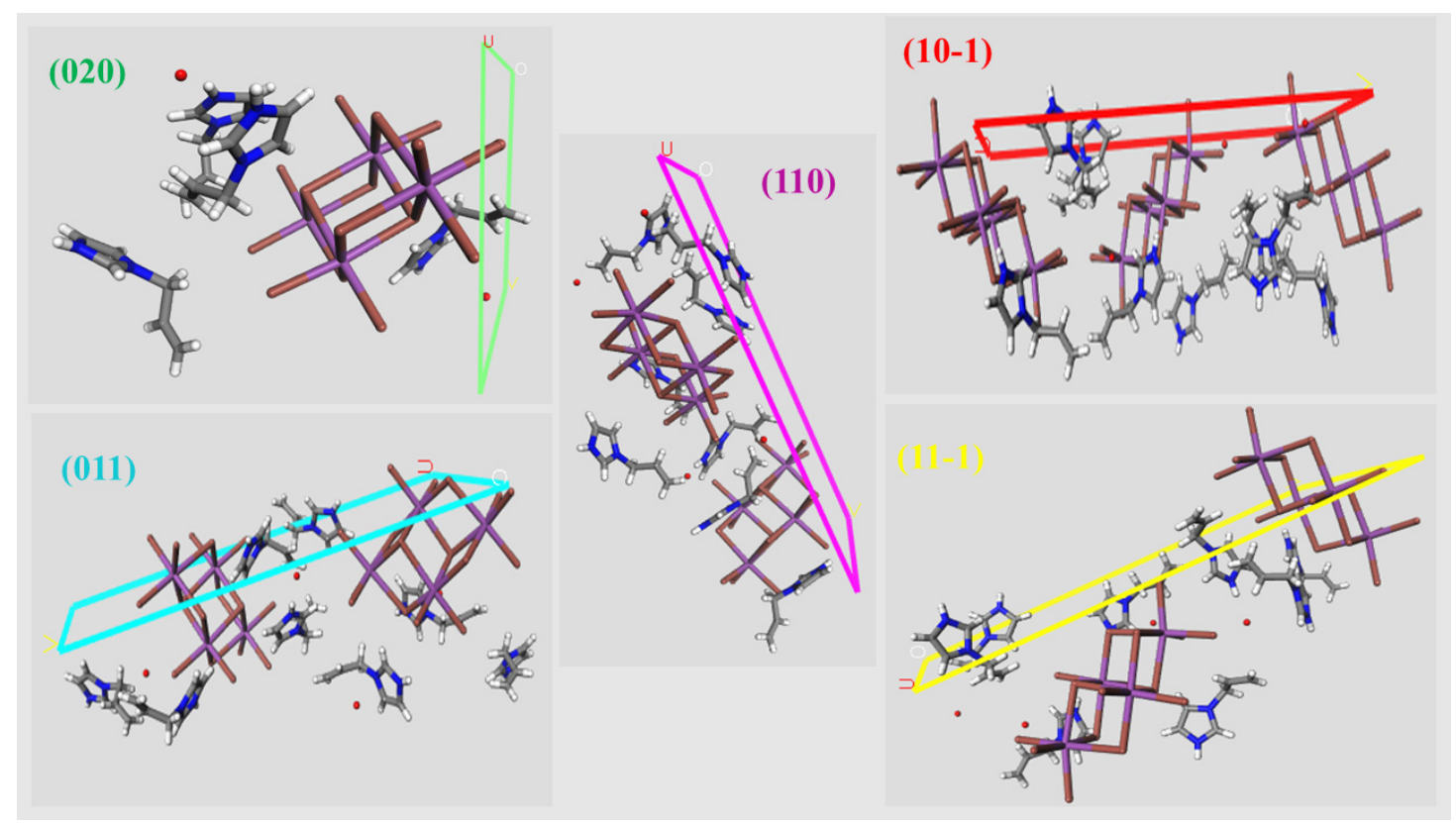

Figure 9. Cleavage structure of main exposure crystal planes of $\mathrm{Bi}_{4} \mathrm{I}_{16} \cdot 4\left(\mathrm{C}_{6} \mathrm{H}_{9} \mathrm{~N}_{2}\right) 2\left(\mathrm{H}_{2} \mathrm{O}\right)$ indicating the presence of different functional groups.

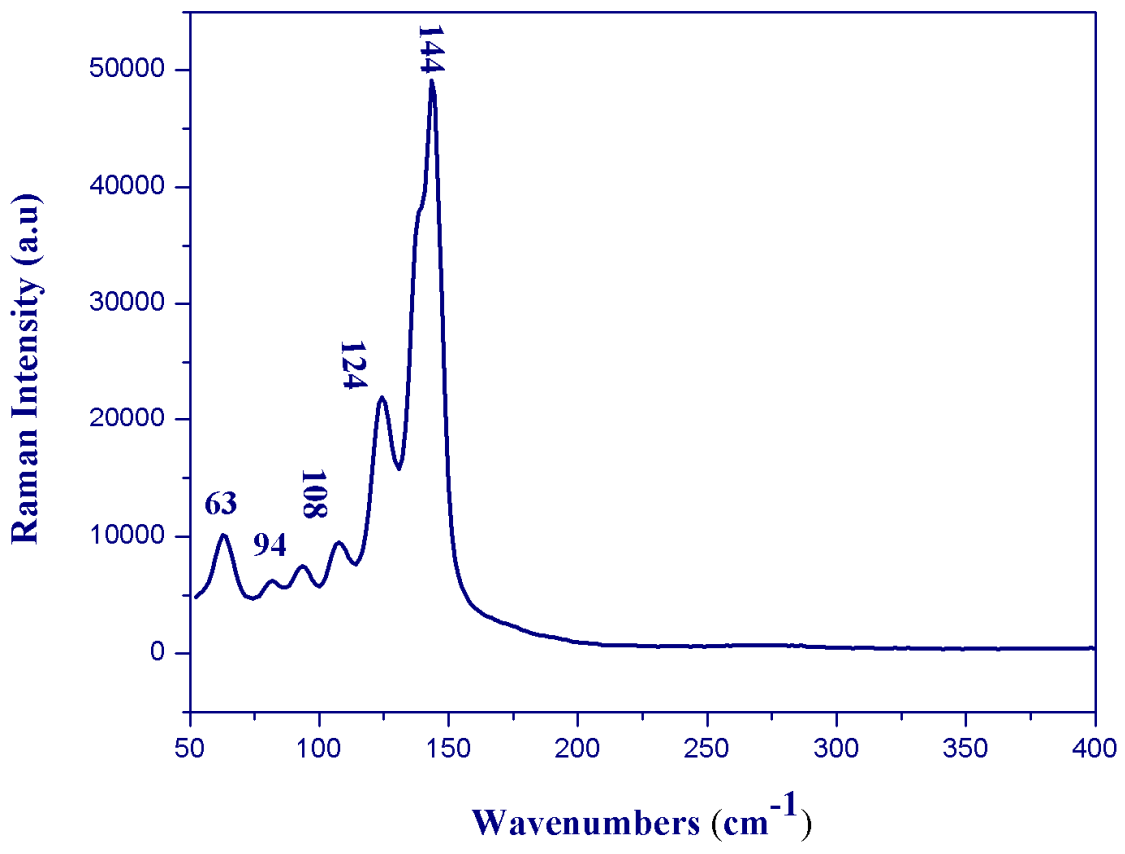

Figure 10. Raman spectrum of $\mathrm{Bi}_{4} \mathrm{I}_{16} \cdot 4\left(\mathrm{C}_{6} \mathrm{H}_{9} \mathrm{~N}_{2}\right) \cdot 2\left(\mathrm{H}_{2} \mathrm{O}\right)$.

The infrared spectrum (Figure 11) recorded between 400 and $4000 \mathrm{~cm}^{-1}$ shows, at high wavenumbers, an absorption at $3546 \mathrm{~cm}^{-1}$ assignable to $\mathrm{N}-\mathrm{H}$ stretching modes. The weak bands between 2924 and $2824 \mathrm{~cm}^{-1}$ are assigned to $(\mathrm{C}-\mathrm{H})$ stretching modes. The peaks observed at 1623 and $1265 \mathrm{~cm}^{-1}$ correspond to stretching vibrations of $(C=N)$ and $(C-N)$ bonds, respectively. $C=C$ and $C-C$ stretching vibrations are observed at $1402 \mathrm{~cm}^{-1}$ and $1046 \mathrm{~cm}^{-1}$, respectively. The bands corresponding to the deformation (CC) and (CN) groups appeared in the $996-800 \mathrm{~cm}^{-1}$ range. The vibrations at $736 \mathrm{~cm}^{-1}$ and $612 \mathrm{~cm}^{-1}$ were due to the deformation $(\mathrm{C}-\mathrm{H})$ of the imidazolium group. Finally, the bands at $550 \mathrm{~cm}^{-1}$ and $439 \mathrm{~cm}^{-1}$ were associated with the rocking and wagging vibrations of $\mathrm{C}-\mathrm{H}$ and $\mathrm{N}-\mathrm{H}$ bands. 


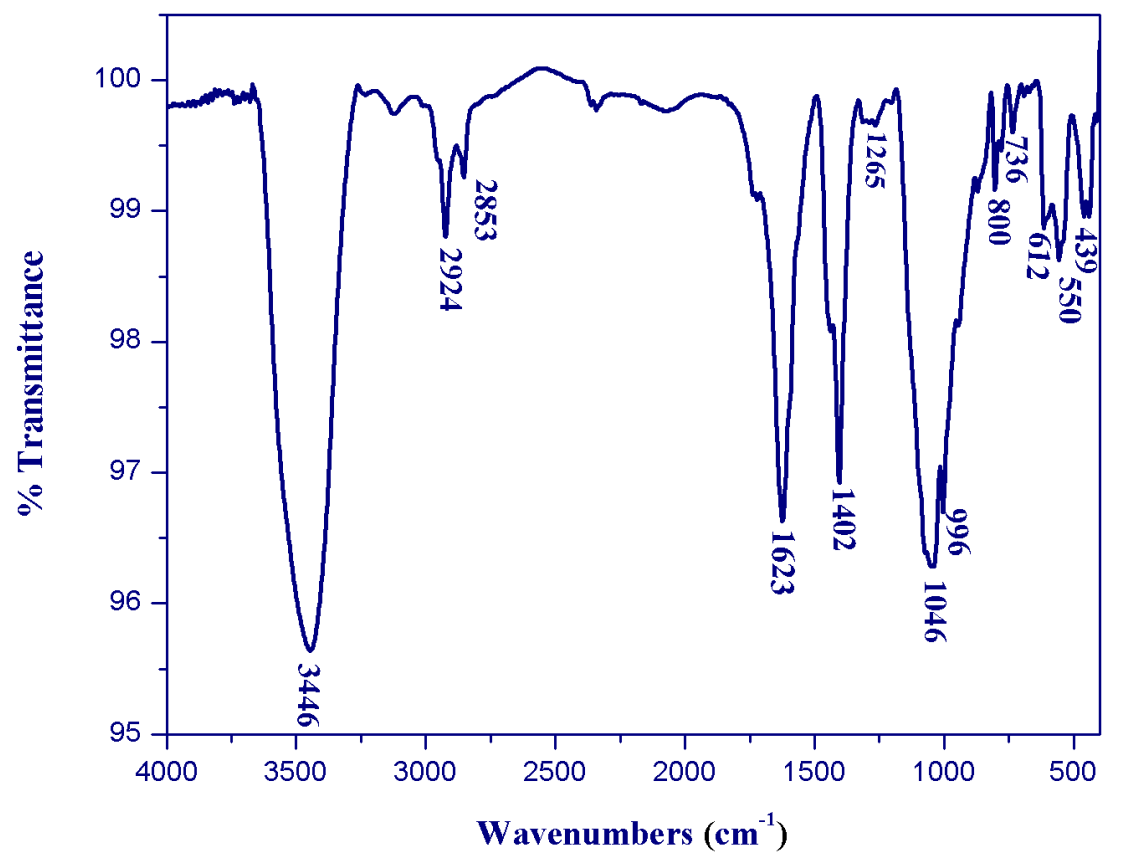

Figure 11. Vibrational spectrum of $\mathrm{Bi}_{4} \mathrm{I}_{16} \cdot 4\left(\mathrm{C}_{6} \mathrm{H}_{9} \mathrm{~N}_{2}\right) \cdot 2\left(\mathrm{H}_{2} \mathrm{O}\right)$.

\section{Conclusions}

The crystal structure of the new organic-inorganic material $\mathrm{Bi}_{4} \mathrm{I}_{16} \cdot 4\left(\mathrm{C}_{6} \mathrm{H}_{9} \mathrm{~N}_{2}\right) \cdot 2\left(\mathrm{H}_{2} \mathrm{O}\right)$ was determined. This compound crystallizes in the monoclinic system at room temperature. The crystal structure is formed by an alternation of organic and inorganic entities linked via hydrogen bonds developing a three-dimensional structure. The Hirshfeld surface analysis of the crystal structure clarifies that the most important contribution for crystal packing is from $\mathrm{H} \cdots \mathrm{I}(56.3 \%)$ and $\mathrm{H} \cdots \mathrm{H}(11.7 \%)$ interactions and confirms the presence of I...I interactions between inorganic clusters. The predicted morphology was compared with the results based on BFDH and GM models and with the experimentally observed morphology. The main crystal facets (002), (101), (011), and (012) were observed to be dominant in the morphology predicted by the two models. By cleaving these dominant crystal facets, surface chemistry visualization and theoretical analysis based on the presence of polar groups (H-band interactions) for the important morphological forms were achieved. Finally, the experimental IR and Raman spectra allowed us to assign the vibration modes present in the title compound.

Supplementary Materials: The following are available online at http://www.mdpi.com/2073-4352/10/5/397/s1, Figure S1. SEM image, EDS spectrum and qualitative results of $\mathrm{Bi}_{4} \mathrm{I}_{16} \cdot 4\left(\mathrm{C}_{6} \mathrm{H}_{9} \mathrm{~N}_{2}\right) 2\left(\mathrm{H}_{2} \mathrm{O}\right)$ single crystal; Table S1. Fractional atomic coordinates and isotropic or equivalent isotropic displacement parameters $\left(\AA^{2}\right)$. CCDC-1908070 contains the supplementary crystallographic data for $\mathrm{Bi}_{4} \mathrm{I}_{16} \cdot 4\left(\mathrm{C}_{6} \mathrm{H}_{9} \mathrm{~N}_{2}\right) 2\left(\mathrm{H}_{2} \mathrm{O}\right)$. These data can be obtained free of charge from The Cambridge Crystallographic Data Center via http://www.ccdc.cam.ac.uk/data_request/cif.

Funding: This research received no external funding.

Conflicts of Interest: The authors declare no conflict of interest.

\section{References}

1. Ali, S.B.; Ferretti, V.; Bianco, L.D.; Spizzo, F.; Belhouchet, M. Structural, vibrational, optical properties and theoretical studies of a new organic inorganic material: Tris-acetoguanaminium hexachlorobismuthate monohydrate. J. Mol. Struct. 2020, 1199, 126986. [CrossRef]

2. Zhang, R.; Mao, X.; Yang, Y.; Yang, S.; Zhao, W.; Wumaier, T.; Wei, D.; Deng, W.; Han, K. Air-Stable, Lead-Free Zero-Dimensional Mixed Bismuth-Antimony Perovskite Single Crystals with Ultrabroad Band Emission. Angew. Chem. Int. Ed. 2019. [CrossRef]

3. Wei, Y.; Cheng, Z.; Lin, J. An overview on enhancing the stability of lead halide perovskite quantum dots and their applications in phosphor-converted LEDs. Chem. Soc. Rev. 2019, 48, 310. [CrossRef] [PubMed] 
4. Szklarz, P.; Jakubas, R.; Piecha-Bisiorek, A.; Bator, G.; Chanski, M.; Medycki, W.; Wuttke, J. Organic-inorganic hybrid crystals, $\left(2,4,6-\mathrm{CH}_{3} \mathrm{PyH}\right)_{3} \mathrm{Sb}_{2} \mathrm{Cl}_{9}$ and $(2,4,6-\mathrm{CH} 3 \mathrm{PyH}) 3 \mathrm{Bi} 2 \mathrm{Cl}$. Crystal structure characterization and tunneling of $\mathrm{CH} 3$ groups studied by $1 \mathrm{H}$ NMR and neutron spectroscopy. Polyhedron 2018, 139, 249-256. [CrossRef]

5. Igbari, F.; Wang, Z.K.; Liao, L.S. Progress of Lead-Free Halide Double Perovskites. Adv. Energy Mater. 2019, 1803150. [CrossRef]

6. Zhou, C.; Lin, H.; Neu, J.; Zhou, Y.; Chaaban, M.; Lee, S.; Worku, M.; Chen, B.; Clark, R.J.; Cheng, W.; et al. Green Emitting Single-Crystalline Bulk Assembly of Metal Halide Clusters with NearUnity Photoluminescence Quantum Efficiency. ACS Energy Lett. 2019, 4, 1579-1583. [CrossRef]

7. Ahern, J.C.; Nicholas, A.D.; Kelly, A.W.; Chan, B.; Pike, R.D.; Patterson, H.H. A terbium chlorobismuthate(III) double salt: Synthesis, structure, and photophysical properties. Inorg. Chim. Acta 2018, 478, 71-76. [CrossRef]

8. AKelly, W.; Nicholas, A.; Ahern, J.C.; Chan, B.; Patterson, H.H.; Pike, R.D. Alkali metal bismuth (III) chloride double salts. J. Alloy. Compd. 2016, 670, 337-345. [CrossRef]

9. Sorg, J.R.; Wehner, T.; Matthes, P.R.; Sure, R.; Grimme, S.; Heine, J.K. Müller- Buschbaum. Bismuth as a versatile cation for luminescence in coordination polymers from $\mathrm{BiX} 3 / 4,4^{\prime}$-bipy: Understanding of photophysics by quantum chemical calculations and structural parallels to lanthanides. Dalton. Trans. 2018, 47, 7669-7681. [CrossRef] [PubMed]

10. Wagner, B.; Dehnhardt, N.; Schmid, M.; Klein, B.P.; Ruppenthal, L.; Müller, P.; Zugermeier, M.; Gottfried, J.M.; Lippert, S.; Halbich, M.U.; et al. Color change effect in an organic-inorganic hybrid material based on a porphyrin diacid. J. Phys. Chem. C 2016, 120, 28363-28373. [CrossRef]

11. Frolova, L.A.; Anokhin, D.V.; Piryazev, A.A.; Luchkin, S.Y.; Dremova, N.N.; Troshin, P.A. Highly Efficient All-Inorganic Planar Heterojunction Perovskite Solar Cells Produced by Thermal Coevaporation of CsI and PbI2. J. Phys. Chem. Lett. 2017, 8, 67-72. [CrossRef] [PubMed]

12. Fabian, D.M.; Ardo, S. Hybrid organic-inorganic solar cells based on bismuth iodide and 1,6hexanediammonium dication. J. Mater. Chem. A 2016, 4, 6837-6841. [CrossRef]

13. Sichert, J.A.; Hemmerling, A.; Daw, C.C.; Urban, A.S.; Feldmann, J. Tuning the optical bandgap in layered hybrid perovskites through variation of alkyl chain length. APL Mater. 2019, 7, 041116. [CrossRef]

14. Ganose, A.M.; Savory, C.N.; Scanlon, D.O. Beyond methylammonium lead iodide: Prospects for the emergent field of $\mathrm{ns}^{2}$ containing solar absorbers. Chem. Commun. 2017, 53, 20. [CrossRef] [PubMed]

15. Adonin, S.A.; Sokolov, M.N.; Fedin, V.P. Polynuclear halide complexes of Bi(III): From structural diversity to the new properties. Coord. Chem. Rev. 2016, 312, 1-21. [CrossRef]

16. Adonin, S.A.; Gorokh, I.D.; Novikov, A.S.; Samsonenko, D.G.; Yushina, I.V.; Sokolov, M.N.; Fedin, V.P. Halobismuthates with halopyridinium cations: Appearance or non-appearance of unusual colouring. Cryst. Eng. Commun. 2018, 20, 776. [CrossRef]

17. Adonin, S.A.; Usoltsev, A.N.; Novikov, A.S.; Kolesov, B.A.; Fedin, V.P.; Sokolov, M.N. One- and Two-Dimensional Iodine-Rich Iodobismuthate(III) Complexes: Structure, Optical Properties, and Features of Halogen Bonding in the Solid State. Inorg. Chem. 2020, 59, 3290-3296. [CrossRef]

18. Adonin, S.A.; Sokolov, M.N.; Fedin, V.P. Bismuth(III) Halide Complexes: New Structural Types and New Application Areas. Russ. J. Inorg. Chem. 2017, 62, 1789-1796. [CrossRef]

19. AUsoltsev, N.; Elshobaki, M.; Adonin, S.A.; Frolova, L.A.; Derzhavskaya, T.; Abramov, P.A.; Anokhin, D.V.; Korolkov, I.V.; Luchkin, S.Y.; Dremova, N.N.; et al. Polymeric iodobismuthates $\left\{\left[\mathrm{Bi}_{3} \mathrm{I}_{10}\right]\right\}$ and $\left\{\left[\mathrm{BiI}_{4}\right]\right\}$ with N-heterocyclic cations: Promising perovskite-like photoactive materials for electronic devices. J. Mater. Chem. A 2019, 7, 5957-5966. [CrossRef]

20. Attia, S.; Chaari, N.; Chaabouni, S. Synthesis, Crystal Structure, and Dielectric Properties of (3-Aminopropylimidazolium) Pentachlorobismuthate(III) $\left[\mathrm{C}_{6} \mathrm{H}_{13} \mathrm{~N}_{3}\right] \mathrm{BiCl}_{5}$. J. Cluster. Sci. 2015. [CrossRef]

21. Sharutin, V.V.; Yegorova, I.V.; Klepikov, N.N.; Boyarkina, E.A.; Sharutin, O.K. Synthesis and structure of bismuth complexes $\left[\mathrm{Ph}_{3} \mathrm{MeP}\right]^{6+}\left[\mathrm{BiI}_{3} \mathrm{Br}_{3}\right]^{3-}\left[\mathrm{Bi}_{2} \mathrm{I}_{6} \mathrm{Br}_{3}\right]^{3-} \cdot \mathrm{H}_{2} \mathrm{O}_{2},\left[\mathrm{Ph}_{3} \mathrm{EtP}\right]^{3+}\left[\mathrm{Bi}_{2} \mathrm{I}_{9}\right]^{3-}, \mathrm{n}\left[\mathrm{Ph}_{3} \mathrm{MeP}\right]^{3+}\left[\mathrm{Bi}_{3} \mathrm{I}_{12}\right]^{3-}$, $\left[\mathrm{Ph}_{3}(\text { iso-Pr) } \mathrm{P}]^{3+}\left[\mathrm{Bi}_{3} \mathrm{I}_{12}\right]^{3-} .2 \mathrm{Me}_{2} \mathrm{C}=\mathrm{O}\right.$, and $\left[\mathrm{Ph}_{4} \mathrm{Bi}^{3+}\left[\mathrm{Bi}_{5} \mathrm{I}_{18}\right]^{3-}\right.$. Russ. J. Inorg. Chem. 2009, 54, 52. [CrossRef]

22. Yelovik, N.A.; Shestimerov, T.A.; Bykov, M.A.; Wei, Z.; Dikarev, E.V.; Shevelkov, A.V. Synthesis, structure, and properties of $\mathrm{LnBiI}_{6} \cdot 13 \mathrm{H}_{2} \mathrm{O}(\mathrm{Ln}=\mathrm{La}, \mathrm{Nd})$. Russ. Chem. Bull. 2017, 66, 1196. [CrossRef]

23. Krautscheid, $\mathrm{H}$. Synthese und Kristallstrukturen von $\left(\mathrm{Ph}_{4} \mathrm{P}\right)_{4}\left[\mathrm{Bi}_{8} \mathrm{I}_{28}\right],\left(\mathrm{nBu}_{4} \mathrm{~N}\right)\left[\mathrm{Bi}_{2} \mathrm{I}_{7}\right]$ und $\left(\mathrm{Et}_{3} \mathrm{PhN}_{2}\left[\mathrm{Bi}_{3} \mathrm{I}_{11}\right]^{-}\right.$ Iodobismutate mit isolierten bzw polymeren Anionen. Z. Anorg. Allg. Chem. 1995, 621, 2049. [CrossRef]

24. Buikin, P.A.; Rudenko, A.Y.; Baranchikov, A.E.; Ilyukhin, A.B.; Kotov, V.Y. 1D-Bromobismuthates of Dipyridinoalkane Derivatives. Russ. J. Coord. Chem. 2018, 44, 373-379. [CrossRef] 
25. Shestimerova, T.A.; Yelavik, N.A.; Mironov, A.V.; Kuznetsov, A.N.; Bykov, M.A.; Grigorieva, A.V.; Utochnikova, V.V.; Lepnev, L.S.; Shevelkov, A.V. From Isolated Anions to Polymer Structures through Linking with $\mathrm{I}_{2}$ : Synthesis, Structure, and Properties of Two Complex Bismuth(III) Iodine Iodides. Inorg. Chem. 2018, 57, 4077. [CrossRef] [PubMed]

26. Zhang, Z.P.; Feng, Q.Y.; Wang, Q.L.; Huang, X.; Chen, D.; Zhou, J. A New Iodobismuthate-Based Hybrid Containing Mixed Iodobismuthate Clusters Templated by Diammonium Cation: Structure and Photocurrent Response. J. Cluster. Sci. 2018, 29, 367. [CrossRef]

27. Bruker APEX3; Bruker AXS Inc.: Madison, WI, USA, 2017.

28. Bruker SAINT; Bruker AXS Inc.: Madison, WI, USA, 2017.

29. Sheldrick, G.M. SADABS Bruker; AXS Inc.: Madison, WI, USA, 2017.

30. Sheldrick, G.M. Crystal structure refinement with SHELXL. Acta Cryst. 2015, C71, 3-8.

31. Brandenburg, K. DIAMOND; Crystal Impact GbR: Bonn, Germany, 2008.

32. Wolff, S.K.; Grimwood, D.J.; McKinnon, J.J.; Turner, M.J.; Jayatilaka, D.; Spackman, M.A. Crystal Explorer (Version 3.1); University of Western: Perth, Australia, 2012.

33. Spackman, M.A.; Jayatilaka, D. Hirshfeld surface analysis. CrystEngComm 2009, 11, 19. [CrossRef]

34. McKinnon, J.J.; Jayatilaka, D.; Spackman, M.A. Towards quantitative analysis of intermolecular interactions with Hirshfeld surfaces. Chem. Commun. 2007, 37, 3814-3816. [CrossRef]

35. Bondi, A. Van der Waals Volumes and Radii of Metals in Covalent Compounds. J. Phys. Chem. 1966, 70, 3006-3007. [CrossRef]

36. Jelsch, C.; Ejsmont, K.; Huder, L. The enrichment ratio of atomic contacts in crystals, an indicator derived from the Hirshfeld surface analysis. IUCrJ 2014, 1, 119-128. [CrossRef] [PubMed]

37. Materials Studio, Version 7.0; Accelrys Software Inc.: San Diego, CA, USA, 2013.

38. Rappe, A.K.; Casewit, C.J.; Colwell, K.S.; Goddard, W.A., III; Skiff, W.M. UFF, a full periodic table force field for molecular mechanics and molecular dynamics simulations. J. Am. Chem. Soc. 1992, 114, 10024-10035. [CrossRef]

39. Goforth, A.M.; Gardinie, J.R.; Smith, M.D.; Peterson, L.R.; Loye, H.C.Z. [Ru(2,2'-bipy)3]2[Bi4I 16]: A bimetallic inorganic-organic complex consisting of a d-metal coordination cation and a polynuclear iodobismuthate anion. Inorg. Chem. Commun. 2005, 8, 684-688. [CrossRef]

40. Carmalt, C.J.; Farrugia, L.J.; Norman, N.C. Synthesis and X-ray Crystal Structure of a Polymeric Iodobismuthate Anion. Z. Naturforsch. B 1995, 50, 1591-1596. [CrossRef]

41. Kubiak, R.; Ejsmont, K. Crystal structure of a novel bismuth phthalocyanine-bismuth iodide complex. J. Mol. Struct. 1999, 474, 275-281. [CrossRef]

42. Bondi, A.J. van der Waals Volumes and Radii. J. Phys. Chem. 1964, 68, 441-451. [CrossRef]

43. GDestri, L.; Marrazzo, A.; Rescifina, A.; Punzo, F. Crystal Morphologies and Polymorphs in Tolbutamide Microcrystalline Powder. J. Pharm. Sci. 2013, 102, 73-83. [CrossRef] [PubMed]

44. Hartman, P.; Bennema, P. The attachment energy as a habit controlling factor: I. Theoretical considerations. J. Cryst. Growth. 1980, 49, 145-156. [CrossRef]

45. Piecha, A.; Jakubas, R.; Pietraszko, A. Phase transitions and electric properties of imidazolium chlorobismuthate(III): $\left[\mathrm{C}_{3} \mathrm{H}_{5} \mathrm{~N}_{2}\right]_{6}\left[\mathrm{Bi}_{4} \mathrm{Cl}_{18}\right]$. J. Mol. Struct. 2007, 829, 149. [CrossRef]

46. Belkyal, I.; Mokhlisse, R.; Tanouti, B.; Chanh, N.B.; Couzi, M. X-ray Diffraction and Raman Scattering in $\left(\mathrm{CH}_{3} \mathrm{NH}_{3}\right)_{3} \mathrm{Bi}_{2} \mathrm{Cl}_{9}$ (MACB) Single Crystals. Phys. Stat. Sol. 1993, 136, 45. [CrossRef]

47. Kuok, M.H.; Ng, S.C.; Iwata, M.; Ishibashi, Y. A Raman study of the phase transition in $\left(\mathrm{CH}_{3} \mathrm{NH}_{3}\right)_{5} \mathrm{Bi}_{2} \mathrm{Cl}_{11}$. Solid State Commun. 1993, 86, 151. [CrossRef]

48. Carpentier, P. Étude des transitions de phase du cristal ferroélectrique (CH3NH3)5BI2CL11 (PMACB): structure et dynamique Phase transitions study of the ferroelectric crystal (CH3NH3)5BI2CL11 (MAPCB). Thesis, Universite of Lille 1, Lille, France, 1995. Available online: http://ori-nuxeo.univ-lille1.fr/nuxeo/site/ esupver (accessed on 15 May 2020).

49. Hooper, M.A.; James, D.W. Vibrational spectra of some Group Vb halides. III. A far-infrared and Raman spectral study of some Hexahalogeno-, Pentahalogeno-, and Tetrahalogeno-bismuthate(III) and -antimonate(III) salts. Aust. J. Chem. 1973, 26, 1401. [CrossRef] 